\title{
A Neurologist Looks at Mind and Brain: "The Enchanted Loom"
}

\author{
Phiroze Hansotia, MD, Emeritus Physician, Department of Neurology, Marshfield Cinic, Marshfield, Wisconsin
}

\author{
REPRINT REQUESTS: \\ Phiroze Hansotia, MD \\ Emeritus Physician \\ Department of Neurology \\ Mailstop: 1R1 \\ Marshfield Oinic \\ 1000 North Oak Avenue 1R1 \\ Marshfield, WI 54449 \\ Email: hansotia@tznet.com
}

\section{KEYWORDS:}

History of medicine; Neurophysiology; Developmental neurobiology; Parietal lobe; Mind

\begin{abstract}
For a long time, before we developed an appreciation of the neuroanatomy and neurophysiology of the brain, there was uncertainty as to the nature and source of the human mind. Philosophers linked the mind to mythical "humors" that controlled the human body, and others speculated that the mind was associated with "life-force" or soul. Few felt that there was a relation between the human mind and brain, but they had to wait for the Age of Enlightenment and scientific discovery in the 18th and 19th centuries to establish a clear association between the two. Three centuries ago Rene Descartes described the mind as an extracorporeal entity that was expressed through the pineal gland. Descartes was wrong about the pineal, but the debate he set off regarding the relationship between mind and brain rages on.

This review looks at the history of speculation on the mind and the development of ideas that have led to our present understanding of this phenomenon. The basic anatomy and physiology of the brain is reviewed to help us understand the brain's association with the complex function we call mind. This is followed by a look at some syndromes that may result when part of the brain is damaged-the parietal lobe is arbitrarily selected as an example-and the resulting effect on the subject's mind. This assists us in understanding the association of mind and brain, and also to better understanding its components, behavior, function and dysfunction.
\end{abstract}

Clinical Medicine \& Research Volume 1, Number 4: 327-332 ๑2003 Clinical Medicine \& Research http://www.mfldclin.edu/clinmedres 


\section{HISTORICAL BACKGROUND}

"Man must persist in his belief that the incomprehensible is comprehensible, otherwise he would cease to explore."

"The highest happiness of a rational being is to have explored what is explorable and quietly to revere what is inexplorable."

Johan Wolfgang von Goethe ${ }^{1}$

The story of man's struggle to understand his mind and its relationship to his brain stretches back to ancient times. Man has long known that human beings have the unique capacity for thought. Anaximander, the early Greek philosopher of the Milesian school (610 BC), felt that "mind gives body a life force."2 In the 6th century BC, Pythagoras had the notion that "the brain served as the organ of the mind and the temple of the soul. Ancient Greek physicians, before Hippocrates (460 BC), held that life was maintained in the human body by a balance of natural forces.

It was believed that disease was caused by an imbalance between the four "humors"-blood, yellow bile, black bile and phlegm. Food eaten and digested was believed to produce the four primary humors. Blood was thought to originate in the heart, yellow bile in the liver, black bile in the spleen, and phlegm in the brain. Greeks believed that humors were moved and mixed in the body by the driving force of "innate heat," which was a form of energy generated by the heart. This innate heat, in turn, generated the humors from the food that was eaten and kept them in balance. Thus, the essential ingredient of man's composition was innate heat.

The humors bore a direct relationship to the four natural elements-fire, air, earth, and water-and therefore, the four qualities of hot, dry, cold and wet. ${ }^{3}$ These humors, it was speculated, not only controlled body function and life, but also mind and behavior. Vestiges of these beliefs survive in our descriptions of personalities as phlegmatic, sanguine, bilious, etc.

Plato, a younger contemporary of Hippocrates, thought the soul was immortal, moved from body to body, and was vulnerable to angry gods who could inflict insanity, hysteria or epilepsy, which together composed the "sacred disease." Aristotle, a student of Plato, agreed with earlier Hindu, Hebrew and Chinese philosophers that the heart was the source of intelligence, emotion and the body's nerve center.

The brain was thought to cool circulating blood, and neither Plato or Hippocrates addressed the issue of mind directly. Plato's reference to the soul presumably meant "life-force," an entity distinct from mind. Hippocrates, the father of modern medicine, first made the associations between brain and emotion, and pain and thought. He disagreed with the theory of humors and claimed that illness was due to natural causes.

In the 2nd century $\mathrm{AD}$, Claudius Galen, the renowned Roman physician, renewed his belief in the humor theory and the role of natural, vital and animal spirits in life and health. He felt that "vital spirits" formed in the heart and were pumped to the brain, where they mixed with "pneuma" (air found in the cavities of the brain) in the "Rete Mirabile" (a network of blood vessels found in the base of the brain of pigs and some other animals whose anatomy was well known at the time) and were transformed into the "animal spirit."

This spirit trickled into the ventricular cavities of the brain for distribution to the rest of the nervous system. Galen further assigned the lobes of the ventricles to the powers of memory, imagination, cognition and language. The idea that these elements, were components of the mind and were related to physical function was thus given support. Galen's views held sway for 1500 years. $^{4}$

In 1543, the maverick Flemish anatomist Andreas Vesalius broke the mold when he published "De humani corporis fabrica (the structure of the human body)." Conducting anatomical dissections on executed criminals he demonstrated that the "Rete Mirabile" did not exist in man, that the structure of the brain was very different from Galen's drawings, and that the ventricles had no bearing on any "spirits" (figure 1). ${ }^{5} \mathrm{He}$ was branded a heretic and fled to Jerusalem. ${ }^{4}$

The concept of "mind" remained elusive until the 17th century (1596-1650) when Rene Descartes, the father of the subjective and idealistic tradition in modern philosophy, announced the notion of primacy of consciousness, in which the mind knows itself by stating "cogito ergo sum" ("I think therefore I am"). ${ }^{6}$

Discoveries about the structure and function of the brain were slow in coming until the 19th century. It was then that it was determined that specific parts of the brain had specific functions. Early in the 19th century Franz Joseph

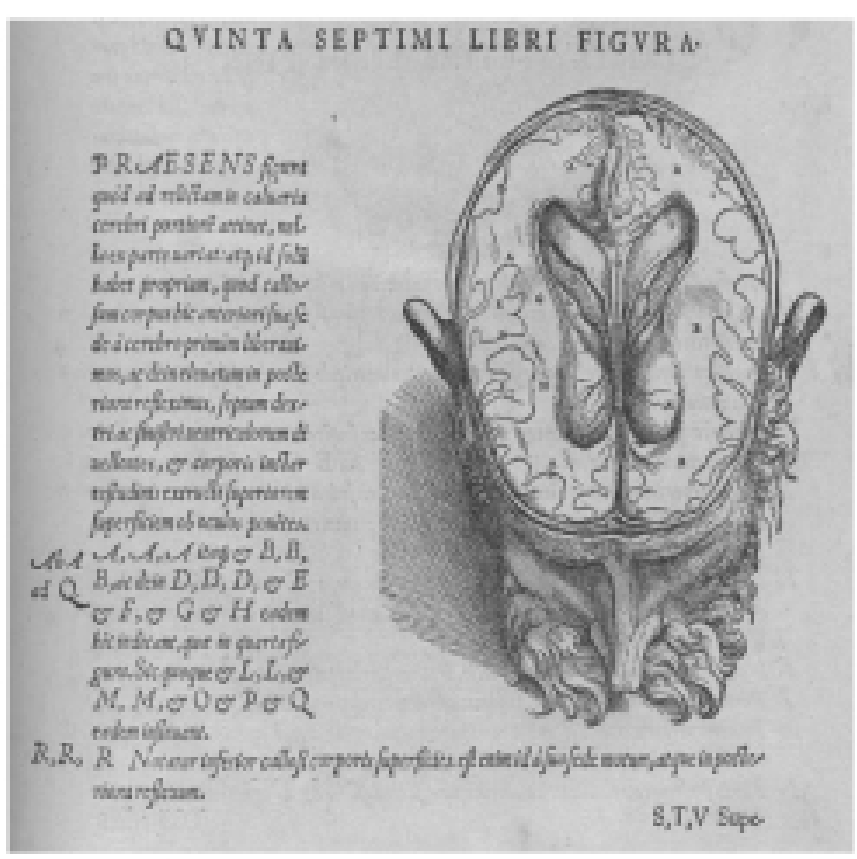

Figure 1. One of Vesalius' illustrations of the dissection of the human brain. Courtesy of the National Library of Medicine. 
Gall developed the pseudoscience of phrenology, predicting mental faculties by examining the bumps and depressions on a person's head. Although phrenology had no merit, it introduced the idea of cerebral localization of mental function. Pierre Flourens tested Gall's theories by slicing away parts of animal brain. Although his cuts were crude and his functional results a bit ambiguous, he demonstrated conclusively that mind and matter were interrelated because damage to certain parts of the brain produced cognitive changes.

In the 1860s, following the Franco-Prussian War, Pierre Paul Broca described aphasia and postulated that language function rested in the left (dominant) hemisphere. ${ }^{4}$ Using electrical stimulation and other techniques, David Ferrier, Korbinian Brodmann, Marie Vogt, Carl Wernicke and others mapped cerebral brain function and designated the various areas by numbers. Some of these designated functional areas are still in common use today. ${ }^{4}$

In the 1870s, John Hughlings Jackson, a neurologist at the National Hospital for Nervous Diseases at Queen Square, London, asserted that the motor centers are the "climax of evolution," and comprise "the organ of the mind." By this he meant that cognition, emotion, memory, insight, imagination and language, all elements associated with the concept of mind, were to be found in the functions of the cerebral hemispheres, leading him to assert that the brain was "the organ of the mind."

Jackson postulated three levels of evolutionary development in the brain: (1) the most primitive level, the brainstem, is concerned with maintaining vital function, (2) the middle level, at the diencephalon (consisting of the thalamus, hypothalamus and epithalamus), is involved with consciousness, and integration of motor and sensory function among other things, (3) the highest level, at the cerebral cortex, is where voluntary movement, sensory perception, language, and mental function reside.

In his studies on evolution, Charles Darwin pointed to the progressive development of the central nervous system with the evolution of the various species of animals, culminating in the largest and most complex brain of man. Other 19th century scholars, including the Prussian Professor of Logic and Metaphysics Immanuel Kant, argued whether the mind evolved with the brain, or existed apart from it. "Why" Darwin reasoned, "is thought being a secretion of the brain, more wonderful than gravity a property of matter?"4

Satirists quipped:

"What is mind?"

"No matter."

"What is matter?"

"Never mind."

In the early 20th century, Russian scientist, Ivan Petrovich Pavlov carried out a series of conditioning experiments on dogs and showed that appropriate stimulation could influence behavior positively or negatively. For example, dogs when offered food, began to salivate in anticipation of eating. If the offering of food was coupled with the ringing of a bell, the dog would soon condition to the stimulus and respond to the ringing of the bell with anticipatory salivation.

John Watson, working at Johns Hopkins University, used the conditioned-reflex mechanism as the basis of all learning, and framed the theory of behaviorism from it. He held that thought was simply speech unuttered. At the same time Sigmund Freud, the Viennese father of psychoanalysis, began the interpretation of the mind based on his anecdotal experiences of human thought, dreams, and behavior.

\section{ANATOMY AND PHYSIOLOGY OF THE BRAIN}

At the end of the 19th and the early part of the 20th century, Santiago Ramon Y Cajal used the method of staining neurons with silver salts developed by Camillo Golgi. The advantage of this technique, which led Cajal to his neurone doctrine, is that silver impregnates some cells in their entirety, but leaves the majority untouched. He realized from his observations that the brain was made up of discrete units rather than a continuous net ("the neuronal doctrine"). ${ }^{7}$ Cajal was able to show that each nerve cell was a distinct body consisting of a nucleus and branching tendrils. Each neuron has one axon that transmits information and several dendrites that receive information. Later scientists would discover that neurons communicated with each other through synapses using electrical impulses and chemical neurotransmitters. ${ }^{4}$

The great neurophysiologist, Sir Charles Sherrington referred to the brain and the central nervous system as the "enchanted loom" where "millions of flashing shuttles weave a dissolving pattern, always a meaningful pattern, though never an abiding one." Its commanding presence orders sensation, movement, thought, a lifetime of memory and dream. ${ }^{4}$

The brain of man and other vertebrates is derived from the embryonic ectoderm. Binary fusion of the zygote results in a small ball of similar cells. The development of the primitive streak and notochord are followed by the development of the neural tube, which also establishes the long axis of the embryo. The neural tube divides into a rostral third which goes on to develop into the brain, and a caudal two-thirds which goes on to become the spinal cord. The rostral third of the neural tube expands into the telencephalon, mesencephalon, and rhombencephalon. The telencephalon, in turn, evolves into the cerebral hemispheres and the diencephalon (thalamus, hypothalamus, and epithalamus). The cerebral hemispheres are divided into the frontal, parietal, occipital, and temporal lobes. Thus it is an intriguing observation that an organ (brain) made from the same material ingredients (nucleated, mitochondria-filled cells) as the liver or kidneys is able to generate the magical, composite function that we call mind. 
The functional unit of the nervous system is the neuron. It consists of a body (soma), dendritic tendrils that receive input, and a single axon that conveys the response of the neuron to other neurons. Messages generated by neurons are conveyed to other neurons at junctional units called synapses. Thus, excitation of an afferent cell leads to conduction of a nerve action potential (the electrical signal generated by excitation of a nerve cell along its axon to its synapse with other neurons). At synapses, the nerve action potential is conducted to other neurons. Chemical mediators, called neurotransmitter substances, convey excitatory or inhibitory neuronal impulses. Each neuron may have 25,000 or more synapses along its dendritic and somatic membranes. The algebraic sum of the impulses generated at the synapses determines the neuronal response.

Activation of large neuronal pools in various areas of the brain result in clinical, behavioral, sensory, or perceptual effects. All functions depend on the smooth interaction between various parts of the brain. The base of the brain consists of the medulla, pons and midbrain, which regulate autonomic functions (including respiration, circulation and digestion) and the cerebellum, which coordinates movement. The cerebral hemispheres contain the limbic system, which control emotional function, long-term memory and other tasks. The cortex, the convoluted surface of the hemispheres controls cognition, speech, language and other functions. The human brain, the most complex object in the universe, comprises a hundred billion neurons linked in networks that give rise to intelligence, emotion, consciousness, memory and creativity. Emerging from the collective activity of all brain regions is the most fascinating neurological phenomenon of all-the mind. ${ }^{8}$

\section{RELATION TO THE BRAIN}

Pavlovian conditioning experiments have established that planned sensory stimulation can be used to induce a learned response and thus behavior. Although the precise neurological correlates of thinking are obscure, we are aware that the thinking process is intimately related to language. Also the frontal, parietal and temporal lobes are actively involved. ${ }^{9}$

The concept of mind encompasses functions that include consciousness, cognition, language, perception, emotion, memory, sleep and dreaming. Thus, we come back to Sherrington's concept of the brain as "an enchanted loom," where "millions of flashing shuttles weave a dissolving pattern, always a meaningful pattern, though never an abiding one."

The parietal lobe first appears in lower mammals, e.g., rabbits. It is more developed in carnivores and primates. The highest level of development is in humans. The parietal lobe is neither an anatomical nor a physiological unit, but merely that part of the convex surface of the cerebral hemispheres that happens to be covered by the parietal bone of the skull.
The parietal lobe lies behind the central sulcus and is limited by the parieto-occipital sulcus and the Sylvian fissure. The parietal lobe has been well studied and can serve as an example of brain-mind relationships. Similar observations can be made on the frontal, temporal, or occipital lobes.

Clinical examination of parietal lobe function includes tests for:

- Sensory acuity: light touch, pinprick sensation, vibration sense, position sense.

- Constructional apraxia: ability to copy a two-dimensional geometrical pattern or to draw a horse, a clock-face, human face, motor car, bicycle, etc.

- Concepts of laterality: ability to point to fingers of the right or left hand and parts of the body.

- Fields of vision: extinction.

- Vocabulary and general intelligence.

- Time sense.

Patients with parietal lobe damage are often unaware of their reduced ability to cope with their daily routine. They are poor witnesses and unreliable subjects for testing. Their responses may be true, false, delayed, or change completely upon retesting. Disorders of body image, including unilateral neglect of motor, sensory or visual function, lack of concern over the existence of hemiparesis (anosognosia), and loss of awareness of half the body are also seen with lesions in this part of the brain. There are different effects with lesions of the right or left parietal lobes. A dominant-hemisphere lesion will affect language and praxis more than a right-hemisphere lesion.

In 1924 Josef Gerstmann described a woman of 52 who demonstrated an inability to recognize her own fingers, to name them, or to point to an individual digit when requested. She also had right-left disorientation and difficulty in calculating and writing. This combination of defects is now called the Gerstmann syndrome and is associated with parietal lobe disease.

Visual agnosia is a neurological disorder often caused by damage to the parietal lobe that is characterized by an inability to recognize familiar objects. There are a vast array of deficits associated with this disorder that vary from individual to individual. For example, some patients with visual agnosia, can point to a cigarette but not to the person smoking it. Another patient may be able to pick out his wife's handbag, but not his wife who is sitting next to him. Some patients demonstrate an indifference to what goes on around them and an inability to switch attention from one concept to the next. They cannot point to various parts of the body, or set the hands of a clock to the current time of day. Such patients cannot read a map, draw from memory, or assemble a jigsaw puzzle. They are also unable to dress, read, or remember a sequence of events, or even find their way home. 
There are also disorders of language and symbolic thought that affect reading, calculating and writing. There are different manifestations depending on whether the disease is unilateral, affecting the right or left lobe, or bilateral, affecting both lobes. ${ }^{10}$

Lastly, parietal lobe disease affects spatial thought. Such lesions cause loss of spatial perception, altered appreciation of dimension, visual disorientation, and loss of attention. There is also a loss of the conception of space and of various spatial manipulations. For example, patients are unable to tell which stick is closer or farther away, or differentiate between a shorter and longer stick. They are unable to count or point accurately to an object in space.

It is now well established that all cortical areas are intimately connected to many other cortical and subcortical areas by axonal and dendritic connections. Strict localization of sign-producing lesions is not the same as localization of function. Parietal signs are often release phenomena and represent activity of some other region of the nervous system. Thus, lesion in other locations may sometimes produce "parietal signs" Flexibility, plasticity, and resilience of cortical functioning can alone explain the clinical phenomena of transience and incompleteness of defect. Lesions outside the parietal lobe can produce disturbances of language, calculation, insight, memory, intelligence and sensory function. 10

Because consciousness is one of the essential elements of the mind, there is a great deal of experimental and clinical medical literature on the neurological substrates of consciousness. ${ }^{11}$ The reticular activating system of the brainstem and diencephalons, the neurons of the cerebral cortex, and neurochemical factors that maintain normal neuronal function and health are all key players in conscious states.

In 1985, Hansotia studied 81 comatose patients over a 2-year period. Including eight who entered the persistent vegetative state. ${ }^{12}$ The vegetative state applies to patients who recover from deep coma, but display an absence of all cognitive function and are limited in their responsiveness to postural and reflexive movements of their limbs and eyes. When this state lasts more than 2 weeks, the term persistent vegetative state is applied. Clinically these patients show no evidence of cognition, emotional function, speech, or language. In the patients with conscious wakefulness and reflexive bodily activity alone, there is no evidence of mind as we know it. Thus, the essential elements of mind are clearly both consciousness and cognition requiring adequate cerebral neuronal function.

Lastly, there is the specter of Alzheimer's disease characterized by progressive loss of cognition, memory function, judgment, insight, emotional control, and a disintegration of language function and perception, resulting in an increasingly vegetative state. These changes are accompanied with progressive cortical atrophy, increasing neuronal plaques and neurofibrillary tangles, and a shrinking brain. The relentless disintegration of mind is accompanied by a parallel atrophy and failure of the brain.

Schwartz and Begley remind us that the debate over the mind-body connection, begun by Descartes, is not over. ${ }^{7,13}$ They summarize the current schools of thought as follows:

- Functionalism focuses on the mind as a function of the brain and a product of its physical activity.

- Epiphenomenalism acknowledges that mind is a real phenomenon but holds that it cannot have any effect on the physical world. From this perspective, consciousness is an epiphenomenon of neuronal processes. In most respects this view finds itself largely in agreement with functionalism.

- Emergent materialism states that mind arises from the brain in a way that cannot be fully predicted from or reduced to brain processes. Mind, on the other hand, may have the power to affect both mental and physical change. This view has not received much support.

- Agnostic physicalism, process philosophy, and dualistic interactionism are all philosophical approaches to the mind-brain issue that were developed before the contemporary level of neurophysiological and clinical knowledge of the brain was attained. None of these carry strong support today.

\section{CONCLUSION}

The debate regarding the relationship between mind and brain opened by Descartes now seems to be at least partially settled by the acquisition of our knowledge of neuroanatomy and neurophysiology. We can now begin to understand this complex system that can control the fingers of a violinist and also send man to the moon. Descartes did not know that the brain is constructed and maintained by both genes and experience, and that it constantly changes through the process of evolution.

The neural connections that form networks and circuits in the brain are essential to the existence of the mind. Generally, when the brain is damaged, so is the mind. We have mapped the various functions to locations in the brain and noted the sequence of neurochemical releases and uptakes that are associated with them. We conclude that the mind is a complex function, an algebraic sum of many functions of the brain. Consciousness and cognition are the essential elements without which the other qualities of mind do not seem to register. All this evidence brings us to the conclusion that the brain is the organ of the mind and that the quality of the mind depends on the quality of the brain. New instruments may need to be developed to further study this complex phenomenon in normal subjects, in neurological disease, and in psychiatric illness. 


\section{ACKNOWLEDGMENTS}

The author wishes to thank Dr. Loren Rolak for his helpful suggestions that assisted with the development of this manuscript and Marshfield Clinic Research Foundation for providing assistance in the preparation of this manuscript through the services of Alice Stargardt and Graig Eldred.

\section{REFERENCES}

1. Radhakrishnan S (editor). Religion and culture. New Delhi: Orient Paperbacks; 1968. p. 90.

2. Russell B. Wisdom of the West, Foulkes P, editor. New York: Crescent Books. 1959.

3. Nuland SB (editor). Doctors: the biography of medicine. 2nd ed. New York: Vintage Books; 1995. p. 13.

4. Pinchot RB, Gersten J (editors). The brain: mystery of matter and mind. Washington DC: US New Books; 1930.

5. Vesalius A. De humani corporis fabrica libri septem. In: Porter $\mathrm{R}$, ed. Cambridge illustrated history of medicine. Basel: Joannes Oporinus; 1543. 156.

6. Durant W. The story of philosophy. New York: Washington Square Press Publication of Pocket Books; 1961. 151.

7. Thompson WR, Melzack R. Early environment. Nerve cells and behaviour. In: Physiological psychology. Chapter 6. Readings from Scientific American. San Francisco: W.H. Freeman and Company; 1971. 147.

8. Fischbach GD. Mind and brain. Sci Am 1992;267:48-57.

9. Schade JP, Ford DH (editors). Basic neurology. Amsterdam: Elsevier; 1965.

10. Critchley M (editor). The parietal lobe. New York: Hafner Publishing Company; 1971.

11. Plum F, Posner JB. The diagnosis of stupor and coma. 3rd ed. Philadelphia: FA Davis Co; 1980.

12. Hansotia PL. Persistent vegetative state. Review and report of electrodiagnostic studies in eight cases. Arch Neurol 1985;42:1048-1052.

13. Schwartz JM, Begley S (editors). The mind and the brain. Neuroplasticity and the power of mental force. New York: Harper Collins; 2002. 